\title{
Modeling and Simulation of Compressed Air System Based on Frequency Conversion
}

\author{
Dahan Zhou*, Aipeng Jiang, Changxin Xing and Junjie $\mathrm{Hu}$ \\ Energy Utilization System and Automation Institute, Hangzhou Dianzi University, Zhejiang, Hangzhou 310018, P R China \\ ${ }^{*}$ Corresponding author
}

\begin{abstract}
Compressed air is considered to be the second electric power energy in the industrial applications, the energy consumption accounted for about $9 \%$ of the national industrial power consumption, study the compressed air system is of great significance. This paper studies the frequency conversion constant pressure of the compressor system, according to the mechanism modeling method to obtain the frequency conversion screw compressor performance model, and the air tank gas pressure and compressor frequency, load relation model, And From the Matlab/simulink platform for single frequency conversion compressor system simulation, have obtained gasholder and compressor under a given load change state, by comparing the frequency conversion constant pressure air compressor system and unloading control energy consumption, shows that frequency conversion constant pressure control strategy can significantly reduce system energy consumption and reduce the gas pressure fluctuations. This study on the analysis of frequency conversion constant pressure of compressed air system running state and selection of actual energy saving strategy, It has significant guidance function.
\end{abstract}

Keywords-energy consumption; frequency conversion; energy saving; modeling

\section{INTRODUCTION}

Compressed air is indispensable in the production of modern industrial, compressed air, water, electricity, and steam called four energy in industry, which is widely used in industry, agriculture, mining, medical industry, is one of the second popularity of electric energy [1].The basic operation mode of the compressed air system including start-stop control, discharge control, the Numbers control, and variable frequency control. In large industrial and mining enterprises and manufacturing, the production of compressed air is often adopts frequency control of motor speed control by means of cluster and air compressor, seldom use single compressor startstop directly or add unloading control. The cluster can be under the control of compressor frequency conversion, also can be the combination of frequency conversion and the frequency conversion compressor, compressor, the kinds of displacement can choose from the actual needs.

Frequency conversion constant pressure compressor system is use the output frequency which is adjusted by the frequency ac voltage as the working voltage of air compressor[3], to change the speed of the air compressor, and control the exhaust, the system principle diagram as shown in figure I, Variable frequency constant pressure of the compressor system is consists of inverter, pressure transmitter, and PID controller adopts the closed-loop control method, the specific control strategy is: take the air compressor system pipe network pressure as a controlled object, through collecting pressure transmitter PT air tank pressure P into electrical signals to the PID regulator.

compared with the pressure setting of the PID controller based on differential generate control signal, the control signal in frequency converter, through working frequency and frequency inverter to control motor speed[5], make the pipe network pressure is closed to the set pressure value. Frequency conversion gas screw machine can better match the industrial site, which is better than the traditional control method of air compressor machine has higher efficiency of energy saving, so the frequency conversion air compressor has been widely used.

For frequency conversion constant pressure compressor control system, this paper established a mathematical model for variable frequency constant pressure compressor system, through the simulation analysis[4], the frequency conversion constant pressure compressor model shows that the variable frequency constant pressure compressor system can largely reduce system energy consumption, and can quickly reach gas demand.

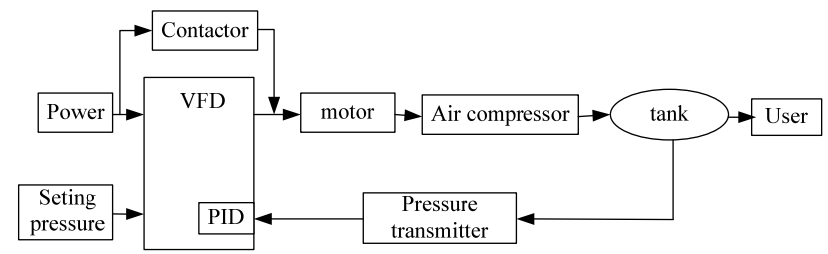

FIGURE I. FREQUENCY CONVERSION CONSTANT PRESSURE COMPRESSOR SYSTEM PRINCIPLE BLOCK DIAGRAM

\section{THE MODELING OF THE SYSTEM OF FREQUENCY CONVERSION SCREW AIR COMPRESSORS}

In the condition of variable frequency, motor speed and frequency can be expressed as :

$$
N=\frac{60 f(1-s)}{p_{n}}
$$

In the formula: $\mathrm{N}-$ The speed of the motor, $\mathrm{r} / \mathrm{min} ; \mathrm{s}-\mathrm{slip}$, Its value is around0.03; $\mathrm{f}$ - The motor frequency, $\mathrm{Hz} ; \mathrm{Pn}-$ The logarithm of a Motor , as $\mathrm{P}_{\mathrm{n}}=2$, the rated speed is $1490 \mathrm{rpm} / \mathrm{min}$; 
Under different frequency, the relationship between volumetric efficiency and the data of measurement take the relative speed, the relative inspiratory capacity to indicated the relationship of volumetric efficiency, it has high accuracy, in this case to establish mathematical model as follows:

$$
\begin{gathered}
\eta_{v_{-} \text {fre }} / \eta_{v}=d_{1}+d_{2}\left(N / N_{\text {ref }}\right)+d_{3}\left(N / N_{\text {ref }}\right)^{3} \\
V_{\text {suc_fre }} / V_{\text {suc }}=\frac{N}{N_{\text {ref }}} \frac{\eta_{v_{-} \text {fre }}}{\eta_{v}}=d_{1}\left(N / N_{\text {ref }}\right) \\
+d_{2}\left(N / N_{\text {ref }}\right)^{2}+d_{3}\left(N / N_{\text {ref }}\right)^{3}
\end{gathered}
$$

As $\mathrm{N}$ is the rotor speed under working frequency, $\mathrm{N}_{\text {fre }}$, $\mathrm{V}_{\text {suc_fre, }} \eta_{\mathrm{v} \_ \text {fre }}$ is compressor speed, inspiratory capacity, volumetric efficiency under state of frequency conversion .d1, d2, d3 Satisfy:

$$
d_{1}+d_{2}+d_{3}=1
$$

According to the above equation, considering the efficiency, the outlet of high pressure gas is equivalent to the amount under the standard conditions as follows:

$$
\begin{gathered}
Q_{o}=V_{\text {suc }} \eta_{v} \\
Q_{O_{-} \text {fre }}=V_{\text {suc_fre }}\left[\eta_{v_{-} \text {fre }}\right.
\end{gathered}
$$

Similarly, In the conditions of frequency conversion, compression power also expressed as related to the phase speed of data fitting form, as the following:

$$
\begin{aligned}
& W_{\text {fre }}=W \frac{V_{\text {suc_fre }}}{V_{\text {suc }}}\left[e_{1}+e_{2}\left(N / N_{\text {ref }}\right)\right. \\
& \left.+e_{3}\left(N / N_{\text {ref }}\right)^{2}\right]
\end{aligned}
$$

Among them, the e1, e2 and e3 satisfy the follows:

$$
e_{1}+e_{2}+e_{3}=1
$$

$\mathrm{d} 1, \mathrm{~d} 2, \mathrm{~d} 3, \mathrm{e} 1, \mathrm{e} 2, \mathrm{e} 3$ is from the data fitting.

TABLE I. THE FITTING PARAMETER TABLE

\begin{tabular}{l|l|l|l|l|l}
\hline $\mathrm{d} 1$ & $\mathrm{~d} 2$ & $\mathrm{~d} 3$ & $\mathrm{e} 1$ & $\mathrm{e} 2$ & $\mathrm{e} 3$ \\
\hline 0.693 & 0.543 & -0.236 & 0.06 & 0.25 & 0.73 \\
\hline
\end{tabular}

Variable frequency control mode is difference with constant speed of air compressor and unloading control[6], as mentioned above, frequency conversion air compressor can be adjusted from the variation of gas motor speed, tracking the change of the gas, the gas supply pressure is within the scope of the value about small fluctuations. In this paper, frequency conversion screw machine adopts PID control to adjust the way of the inverter output frequency control of motor speed, achieve the goal of stable gas supply pressure.

According to the above method to calculate frequency conversion cases, the power and the output of gas[7].The frequency and the relationship between the flow and pressure, the transfer function is:

$$
\begin{aligned}
& Q_{o_{-} \text {fre }}=V_{\text {suc_fre }}\left\lceil\eta_{v_{-} \text {fre }}=V_{\text {suc }} \frac{N}{N_{\text {ref }}} \frac{\eta_{v_{-} \text {fre }}}{\eta_{v}}\right. \\
& =V_{\text {suc }}\left[d_{1}\left(N / N_{\text {ref }}\right)+d_{2}\left(N / N_{r e f}\right)^{2}+d_{3}\left(N / N_{\text {ref }}\right)^{3}\right]
\end{aligned}
$$

For that the frequency and the speed is proportional relationship, so it put as:

$$
\begin{aligned}
& Q_{o_{-} \text {fre }}=V_{\text {suc_fre }}-\eta_{v_{-} \text {fre }}=V_{\text {suc }} \frac{N}{N_{\text {ref }}} \frac{\eta_{v_{-} \text {fre }}}{\eta_{v}}= \\
& V_{\text {suc }}\left[d_{1}\left(f / f_{\text {ref }}\right)+d_{2}\left(f / f_{\text {ref }}\right)^{2}+d_{3}\left(f / f_{\text {ref }}\right)^{3}\right]
\end{aligned}
$$

$$
\Delta m=\beta \Delta Q \cdot \Delta t / \rho_{0} / 29
$$

$$
P_{t 0}=m R T / V_{t}
$$

$$
\Delta P_{t}=\Delta m R T / V_{t}=\frac{\beta \Delta Q \cdot \Delta t R T}{29 \rho_{0} V_{t}}
$$

The frequency is from $\mathrm{f} 0$ change to $\mathrm{f} 0+\Delta \mathrm{f}$, so

$$
\begin{aligned}
& Q_{D_{-} \text {fre }}\left(f_{0}+\Delta f\right)=V_{\text {suc }}\left[d_{1}\left(\left(f_{0}+\Delta f\right) / f_{\text {ref }}\right)+\right. \\
& \left.d_{2}\left(\left(f_{0}+\Delta f\right) / f_{\text {ref }}\right)^{2}+d_{3}\left(\left(f_{0}+\Delta f\right) / f_{\text {ref }}\right)^{3}\right] \\
& =Q_{0}+\Delta Q
\end{aligned}
$$

Remove the second order items and three items, so

$$
\begin{aligned}
& \Delta Q \approx V_{\text {suc }}\left(\frac{d_{1} \Delta f}{f_{\text {ref }}}+\frac{2 d_{2} f_{0} \Delta f}{f_{\text {ref }}{ }^{2}}+\frac{3 d_{3} f_{0}^{2} \Delta f}{f_{\text {ref }}{ }^{3}}\right) \\
& =V_{\text {suc }} \Delta f\left(\frac{d_{1}}{f_{\text {ref }}}+\frac{2 d_{2} f_{0}}{f_{\text {ref }}{ }^{2}}+\frac{3 d_{3} f_{0}^{2}}{f_{\text {ref }}{ }^{3}}\right)
\end{aligned}
$$

$$
\Delta m=\Delta Q \cdot \Delta t / \rho_{0} / 29
$$




$$
P_{t 0}=m R T / V_{t}
$$

$$
\begin{aligned}
& \Delta P_{t}=\beta \Delta m R T / V_{t}=\frac{\beta \Delta t R T \cdot \Delta Q}{29 \rho_{0} V_{t}} \\
& =\frac{\beta \Delta t R T}{29 \rho_{0} V_{t}} \cdot V_{\text {suc }} \Delta f\left(\frac{d_{1}}{f_{\text {ref }}}+\frac{2 d_{2} f_{0}}{f_{\text {ref }}^{2}}+\frac{3 d_{3} f_{0}^{2}}{f_{\text {ref }}^{3}}\right)
\end{aligned}
$$

As $\beta$ less than 1 , take about 0.8 , Indicate the gas which is get into the storage tanks,so

$$
\frac{\Delta P_{t}}{\Delta t} \cong \frac{\mathrm{d} P_{t}}{\mathrm{~d} t}=\frac{\beta R T}{29 \rho_{0} V_{t}} \cdot V_{\text {suc }} \Delta f\left(\frac{d_{1}}{f_{\text {ref }}}+\frac{2 d_{2} f_{0}}{f_{\text {ref }}{ }^{2}}+\frac{3 d_{3} f_{0}^{2}}{f_{\text {ref }}{ }^{3}}\right)
$$

Because of ignoring the second item, and other factors, the model can reflect the basic situation, does not take factors such as leakage into account, take the PID control rule.

\section{THE SIMULATION ANALYSIS OF FREQUENCY CONVERSION SCREW AIR COMPRESSOR}

Now as $250 \mathrm{kw}$ single screw air compressor, the screw machine displacement is $42 \mathrm{~m}^{3} / \mathrm{min}$, adjustable frequency range is 10 to $50 \mathrm{hz}$. Gas-holder is $10 \mathrm{~m}^{3}$, the volume of gas load reference as shown above, a factory actual situation gasholder initial pressure is $0.1 \mathrm{MPa}$, the target of pressure control in $0.6 \mathrm{MPa}$, in accordance with the above mathematical model in simulink platform as shown in Figure 3.

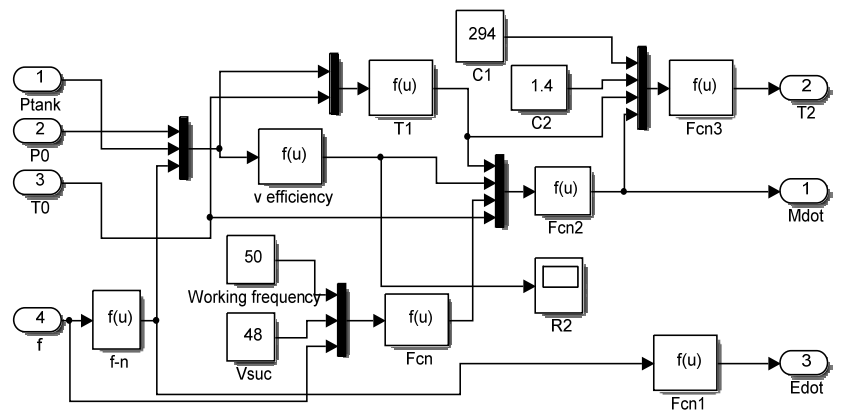

FIGURE II. THE INTERNAL STRUCTURE OF FREQUENCY CONVERSION CONSTANT PRESSURE AIR COMPRESSOR SYSTEM

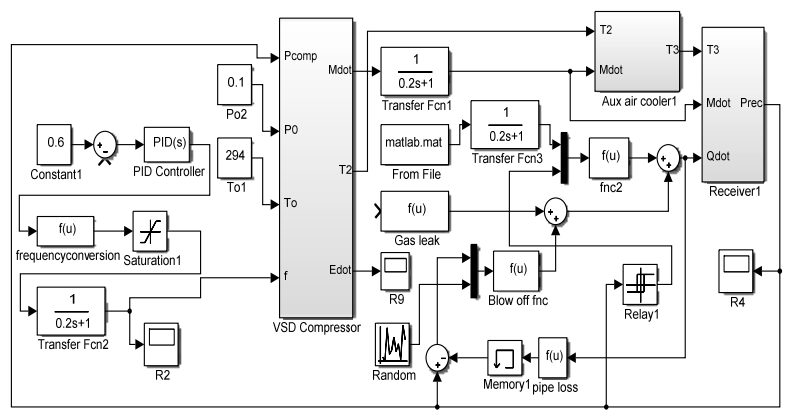

FIGURE III. VARIABLE FREQUENCY CONSTANT PRESSURE AIR COMPRESSOR SYSTEM BLOCK DIAGRAM
For further analysis of gas fluctuation situation inverter screw machine work, assuming an industrial site for 10 minutes gas situation as follows:
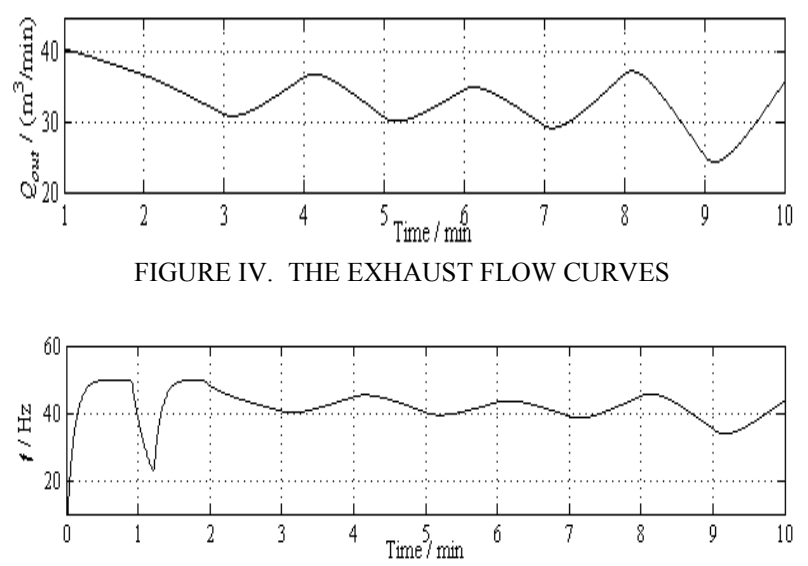

FIGURE V. THE FREQUENCY OF THE CONSTANT PRESSURE AIR COMPRESSOR

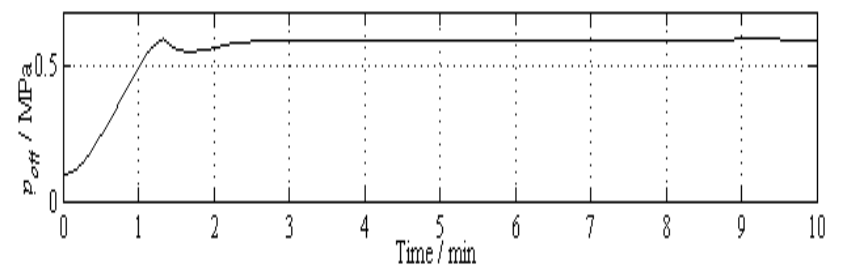

FIGURE VI. THE CHANGE OF RESERVOIR PRESSURE

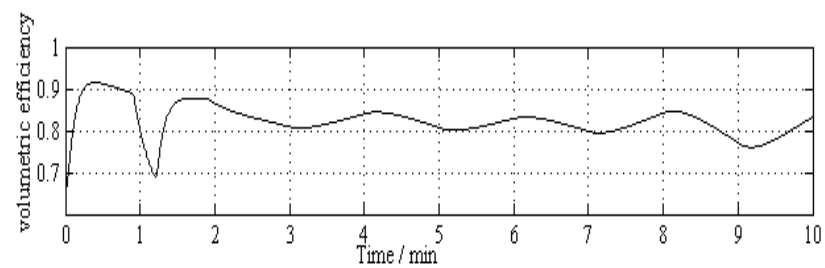

FIGURE VII. THE CURVES OF VOLUMETRIC EFFICIENCY

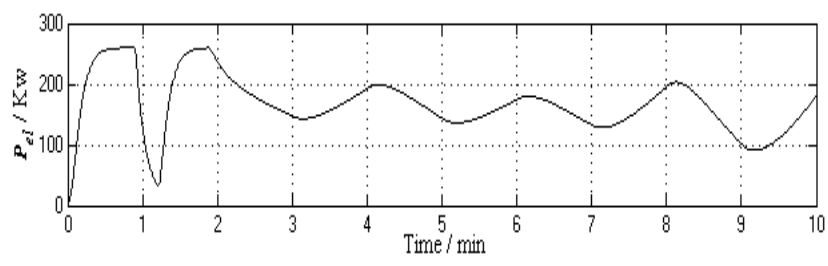

FIGURE VIII. THE SHAFT POWER CURVE OF FREQUENCY CONVERSION CONSTANT PRESSURE AIR COMPRESSOR

At the initial time, In the process of the system startup, the reservoir pressure is $0.1 \mathrm{Mpa}$, the measured value and the given value difference is very large[8], the inverter output frequency increases rapidly, and the speed is increasing, the compressor power increased, the corresponding air tank pressure is also gradually rise, after a period of time filling, pressure differ with the set value of gas storage is more and more small, at this point, the inverter output frequency is reduced, the gas supply to outsiders gas holder. As is shown in Figure6, in the process of gas, air tank pressure to fall again[9], this time the working 
frequency of compressor is rising again. Comparing with the working state of the air compressor curve with the user gas curve, It can be obviously observe the compressor shaft power, working frequency, the trend of volumetric efficiency, exhaust temperature, and the gas demand fluctuation trend is consistent, which can verify the accuracy of the models.

\section{COMPARE CONSTANT SPEED SCREW MACHINE WITH VARIABLE FREQUENCY CONSTANT PRESSURE SCREW MACHINE ENERGY CONSUMPTION}

Frequency conversion constant pressure compressor can improve the system of energy conservation, reduce the cost of operation, but not all cases are the most energy-efficient [2], the inverter and the speed of volumetric efficiency caused by energy consumption of its change will affect the final energy saving situation, and because of the air compressor output frequency of frequency converter itself characteristics is limited to a certain frequency range. For further investigating the energy conservation of frequency conversion screw machine, make as following simulation: set in a certain period of time, under the condition of gas load for different values, calculate frequency and the frequency conversion air compressor power consumption[10].In general, the efficiency of the converter in $95-97 \%$, its power consumption is commonly load rated power of $3-5 \%$, so in the energy consumption of variable frequency constant pressure screw machine to join inverter power consumption. The simulation curve is as follows.

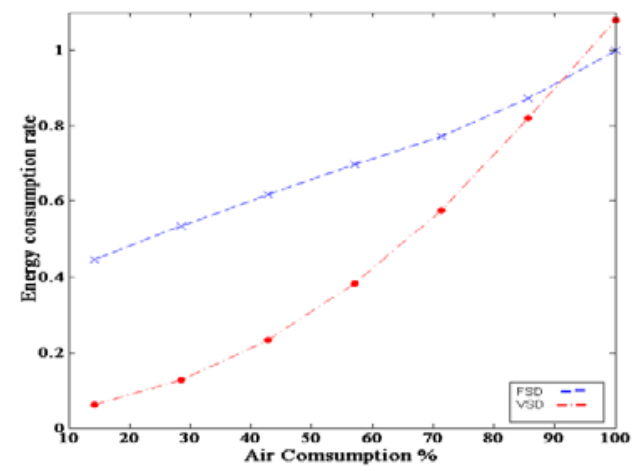

FIGURE IX. COMPARED THE POWER OF FREQUENCY CONVERSION CONTROL AND CONSTANT FREQUENCY CONTROL

According to the above comparison, when Gas load is lower than $90 \%$,enengy consumption of compressor of variable-frequency is littler than constant-frequency. When the gas load is close to rated load, enengy consumption of compressor of constant-frequency is littler than variablefrequency. Further analysis of the causes of the situation: Variable frequency control reduces greatly of the high gas pressure caused by loading and unloading control of additional energy consumption; the compressor under the control of Loading and unloading, in the state of unloading, no gas producted, but the energy consumption is still between 25 to 30 percent, when Variable frequency compressor does not have this problem. When the rate of the load of gas close $100 \%[11]$,Because the inverter's power and speed change contribute to volumetric efficiency degradation. The efficiency of compressor of variable-frequency will be lower than the compressor under the control of loading and unloading[12].

\section{CONCLUSION}

Frequency converter applied to gas control of compressor of constant-pressure can well meet the requirements of control process, and has many advantages of those traditional control method cannot replace. The paper set up constant-pressure and variable-frequency conversion control system of mechanism model and the composition and working principle of the control system is introduced. then simulated on MATLAB/simulink, get the frequency curve and power curve of constant-pressure and variable-frequency compressor, verify the accuracy of models. By comparing the energy consumption of traditional loading and unloading control and variable frequency control, and further analysis on energy consumption of different control strategies reason. and with the development of frequency conversion technology, Its application will continue to expand and strengthen. This study has significant role in theoretical guidance for actual production.

\section{ACKNOWLEDGMENT}

Supported by the Graduate Scientific Research Foundation of Hangzhou Dianzi University.

\section{REFERENCE}

[1] Zhang.Y.B.Inverter application tutorial[M].Beijing China Machine PRESS, 2007;211-214.

[2] Zhang.Y.M,Cao.M.L,Research on new Typical Energy-economizing and Intelligent controller for compressor Grop[J].Hydraulics pneumatics and seals,2008,(05):14-18.

[3] Gao.X.J,Chen.F,Econamic Analysics and Technical Program of Energy conservation for conversion Frequency Screw Air Compressor[J]. Technology of Compressor Refrigeration,2009,(3):19-22.

[4] Qing.H.B,Hu.S.G,Study on optimization potential of Industrial Compresssed air system[J]. Fluid Flow Machine,2010,38(2):49-52.

[5] Zhang.X.J,Xing.Z.W.Experimental Study on the Indicating Diagram of an oil-Injected Twin Screw Compressor[J].Journal of xi,An JiaoTong university.2001,35(05):475-478.

[6] Cao.M.L.Technology to saving Energy about Compressing Air system[J].Fluid power Tranmission and control,2012,(06).

[7] Fu.L.The simulation of the system model of Screw Compressor[J].Compressor Technology,2002,(1):10-11.

[8] L. Yang, L. Zhao, C. Zhang, B. Gu, Loss-efficiency model of single and variable speed compressors using neural networks, International Journal of Refrigeration 32 (2009) 1423-1432.

[9] E.Winandy,C.Saavedra,J.Lebrun,Experimental analysis and simplified modeling of a hermetic scroll refrigeraion compressor,Applies Thermal Engineering 22(2)(2002)107-120.

[10] Markisa T, Paravantisb J A. Energy conservation in small enterprises[J]. Energy \& Buildings, 2007, 39(4):404-415.

[11] Chris B, Joseph G, Henry K, et al. Improving Compressed Air System Performance[M]. U.S. Department of Energy, 2003

[12] Li W.Simplified steady-state modeling for variable speed compressor[J]. Applied Thermal Engineering, 2013, 50(1):318-326 